\title{
Depression and anxiety in the Malaysian urban population and their association with demographic characteristics, quality of life, and the emergence of the COVID-19 pandemic
}

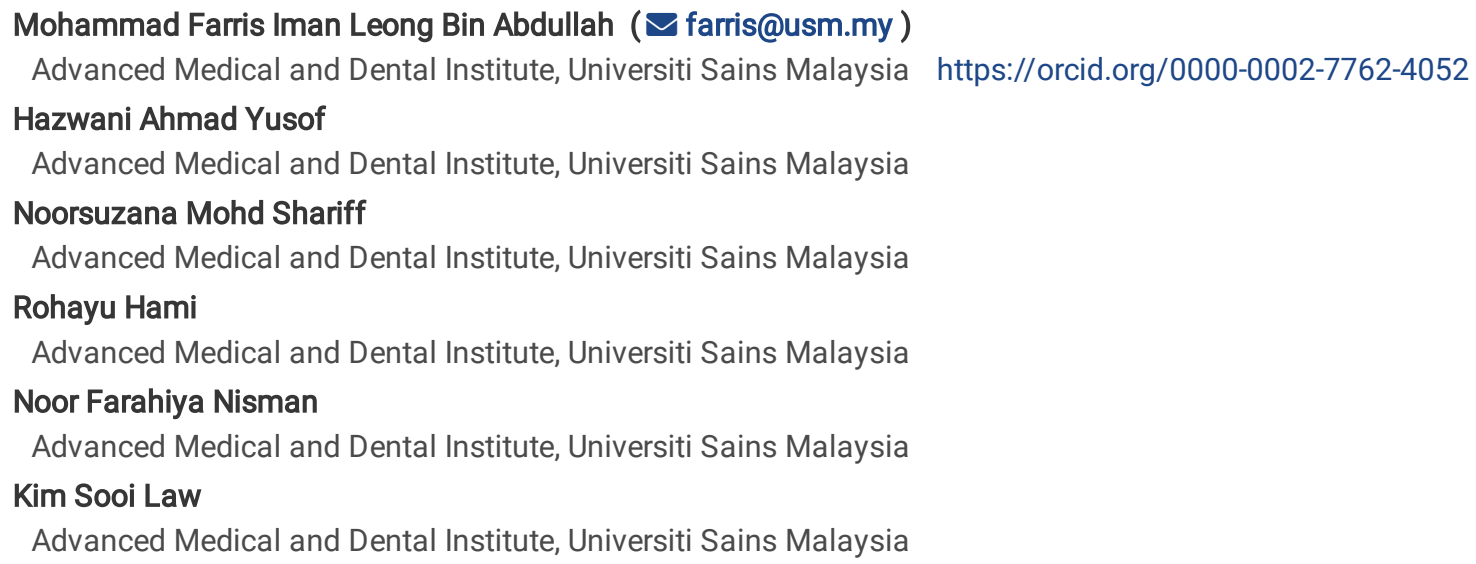

\section{Research Article}

Keywords: Depression, anxiety, depression with comorbid anxiety, urban population, COVID-19

Posted Date: November 24th, 2020

DOI: https://doi.org/10.21203/rs.3.rs-114780/v1

License: (c) (i) This work is licensed under a Creative Commons Attribution 4.0 International License. Read Full License 


\section{Abstract}

The prevalence of depression and anxiety have been shown to be higher in the urban population compared with the rural population. The present study investigated the prevalence of depression, anxiety, and depression with comorbid anxiety and their associated factors in a random sample drawn from several urban communities in Malaysia. This study also compared the odds of developing depression, anxiety, and depression with comorbid anxiety before and after the emergence of the Coronavirus Disease 2019 (COVID-19) pandemic. We recruited 326 participants who were administered a sociodemographic characteristics questionnaire, the 21-item Depression, Anxiety, and Stress Scale (DASS-21), to assess the presence or absence of depression, anxiety, and depression with comorbid anxiety, and the World Health Organization Quality of Life-BREF (WHOQoL-BREF) to assess their QoL. The following prevalence values were obtained among the participants: depression, 23.9\%; anxiety, $41.7 \%$; and depression with comorbid anxiety, $19.9 \%$. The factors significantly associated with higher odds of psychological complications included those assessed after the emergence of COVID-19 as a global pandemic and the presence of comorbid stress. Higher physical health-related QoL, psychological QoL, and environment-related QoL reduced the odds of psychological complications. Based on our findings, we recommended a few measures to curb psychological complications among the urban population, particularly as the battle to contain COVID-19 is still ongoing.

\section{Introduction}

In Malaysia, a developing country in Southeast Asia that is moving forward rapidly in becoming a developed country, $76.04 \%$ of the population was living in urban areas in 2018, representing a threefold increase in urbanization compared with in 1960 (United Nations Department of Economic and Social Affairs, 2018). One of the major concerns associated with urbanization is the negative effect that it imposes on the mental health status of the urban population. Various factors, such as low socioeconomic status, low social capital, higher rates of pollution, and physical threats (e.g., violence and higher crime rates) may increase the risk of developing psychological complications among the urban population compared with the rural population (Gruebner et al., 2017). Hence, it is of pivotal importance to investigate the mental health status of the urban population in a rapidly developing country like Malaysia.

Among the common psychological complications related to urbanization, depression and anxiety are exhibiting a rising trend, not only in the global context but also in Malaysia specifically. Comparing urban with rural settings, the odds of mood disorder and anxiety disorder are almost 1.4-fold and 1.2-fold higher in the urban population (Gruebner et al., 2017). A national mental health survey of 9,656 Colombian respondents in the community showed that the prevalence of depression with comorbid anxiety was $9.6 \%$ in urban respondents compared with only $6.9 \%$ in rural respondents (de Vries et al., 2018). In the Malaysian context, data on the prevalence and associated factors of depression and anxiety in the urban population are still lacking. A study of 301 Malaysian respondents from an urban poor community indicated that the prevalence of depression was at $12.3 \%$, and the factors associated with depression included young age (<25 years old), male gender, lack of physical activity, and living in the community for $<4$ years (Tan and Yadav, 2012). Another study investigated the mental health status of 576 Malaysian adults who attended six primary health clinics; the authors reported that the prevalence of anxiety was $44.5 \%$, that of depression was $20.5 \%$, and that of stress was $10.1 \%$ (Abd Rahman et al., 2020). However, to the best of our knowledge, no study has investigated the quality of life (QoL) of the urban population in Malaysia. In the wake of the emergence of the COVID-19 pandemic, there has been a significant effect on the mental health status of the general population around the world. A systematic review of 19 studies on the psychological consequences of COVID-19 for the general population found that the rates of depressive symptoms $(14.6 \%-48.3 \%)$, anxiety symptoms $(6.33 \%-50.9 \%)$, and stress symptoms $(8.1 \%-81.9 \%)$ were alarming in the general population (Xiong et al., 2020). Nevertheless, data on the comparison of the prevalence of these psychological symptoms among the urban population before and after the emergence of COVID-19 as a global pandemic is not available. To fill this research gap, this study investigated the following issues: (1) the prevalence of depression, anxiety, and depression with comorbid anxiety; and (2) the association between various demographic factors, QoL, and the psychological complications mentioned above among participants sampled from several urban communities in Malaysia. In addition, this study compared the odds of developing depression, anxiety, and depression with comorbid anxiety in the urban population before and after the emergence of COVID-19 as a global pandemic.

\section{Methods}

\section{Study participants}

This cross-sectional study was carried out from July 2019 to August 2020 and recruited people living in six urban communities in the state of Penang located in northern Peninsular Malaysia. Subject recruitment and data collection were temporarily halted from mid-March to early June 2020 due to a movement control order (MCO) imposed by the Malaysian government to curb the increasing spread of COVID-19 within the country. During the MCO, the country was under complete lockdown, where any travel, social, religious, or work-related activities outside the home were prohibited by the government. The research project was resumed from mid-June 2020 and ended in August 2020, which was between 1 week and 2 months after the movement control order was lifted. This study was initially intended to investigate the prevalence of 
psychological complications and its associated factors in the urban population. As the COVID-19 pandemic emerged, we included the comparison of the odds of psychological complications before and after the emergence of the COVID-19 pandemic as one of the objectives of the study. This study received approval from the Human Research Ethics Committee of Universiti Sains Malaysia (code:

USM/JEPeM/19030190). The participants were recruited via simple random sampling by computer-generated random numbers selected according to the house numbers of the population in the six selected communities. Then, the selected people were invited to participate in the study. The selected individuals were eligible to participate in the study if they were at least 18 years old, Malaysian citizen, live in the selected households, and were literate to Bahasa Malaysia (the official language of Malaysia). While they were excluded if they presented with psychotic disorders, bipolar mood disorder, and had history of illicit drug use. The participants who met the eligibility criteria were briefed by the research team regarding the objectives of the study, duration of involvement, risks and benefits of the study, the responsibilities and rights of the participants, and the steps taken to maintain confidentiality of the information disclosed. Written informed consent for study participation was provided by each participant before they enrolled in the study.

\section{Data collection}

The participants completed the demographic characteristics questionnaire; the Malay version of the 21-item Depression, Anxiety, and Stress Scale (DASS-21); and the Malay version of the 26-item World Health Organization QoL-BREF (WHOQoL-BREF) under the supervision of the research team. Demographic data collected include the following: gender, age, employment status, ethnicity, marital status, the time of assessment conducted in relation to the declaration of COVID-19 as a global pandemic, and cigarette smoking. The height and weight of the participants were also measured to compute the body mass index (BMI). The age of the participants was coded into three groups; age of 1830 years was coded as $0,31-60$ years as 1 , and > 60 years as 2 . The gender of the participants was coded as follows: male, 0 ; and female, 1 . The ethnicity of the participants was coded into two groups; non-Malay was coded as 0 and Malay as 1 . The employment status of the participants was also coded into two groups; employed was coded as 0 and unemployed or students as 1 . Marital status was coded into two groups, where married was coded as 0 and unmarried, divorced, or widowed as 1 . The time of assessment conducted in relation to the declaration of coronavirus disease 2019 as a pandemic was coded into two groups, that is, before COVID-19 was declared as a global pandemic which was coded 0 and after COVID-19 was declared as a global pandemic was coded 1 . Finally, cigarette smoking status was coded into two groups; non-smokers were coded as 0 and smokers as 1 .

The DASS-21 is a self-reported instrument to assess the severity levels of anxiety, depressive, and stress symptoms experienced by respondents. It consists of 21 items, which are categorized into three subscales, that is, the anxiety, depression, and stress subscales. Participants were asked to score each item on a Likert scale ranging from 0 to 3 . Sum scores are computed for each subscale by adding the score of each item per subscale and multiplying the sum score with a factor of 2 . Hence, the total score for each subscale ranged from 0 to 42 . The total sum score for the DASS-21 ranged from 0 to 126. The cut-off scores for case findings in DASS-21 are as follows: 9 for the depression subscale, 7 for the anxiety subscale, and 14 for the stress subscale (Lovibond and Lovibond, 1995). The Malay version of the DASS-21 has acceptable internal consistencies with Cronbach's alpha values ranging from 0.74 to 0.84 for its subscales. The 3-factor model of the Malay version of the DASS-21 was also confirmed and most of its items has acceptable factor loading (0.39 to 0.73) (Musa et al., 2007).

The WHOQoL-BREF is a self-reported instrument to assess the QoL of respondents. It comprises 26 items, with items 1 and 2 assessing the perceived QoL and health status of the respondents, and the other items grouped into four domains (environmental, psychological, physical health, and social relationship domains). Participants were asked to score each item on a Likert scale from a range of 1 to 5 . The sum of the scores in each domain can be transformed into a 0- to 100-point scale. The WHOQoL-BREF has acceptable psychometric properties and can be substituted for the WHOQoL-100 to measure QoL without significant loss of information. The sum of the scores in each domain can be transformed into a 0- to 100-point scale (WHOQoL, 1998). The Malay version of the WHOQoL-BREF was validated in the Malaysian population and shown to have good psychometric properties. It has good internal consistency with Cronbach's $a=0.89$ (Hasanah et al., 2003).

\section{Statistical analysis}

All data were analyzed using the Statistical Package for Social Sciences version 26 (SPSS 26; SPSS Inc., Chicago, Illinois, USA). To achieve objective 1 of the study, the descriptive statistics for the demographic characteristics of the participants, the DASS-21 subscale scores, and the WHOQoL-BREF domain scores were computed. All the categorical variables were reported as frequency and percentage, while all the continuous variables as mean and standard deviation (SD). To achieve objective 2 of the study, initially, simple logistic regression was performed to assess the crude odds ratios (crude ORs) of individual demographic characteristics and the WHOQoL-BREF domain scores, and stress (no stress coded as 0 and presence of stress coded as 1 ) in predicting the outcome of depression (no depression coded as 0 and presence of depression coded as 1 ), anxiety (no anxiety coded as 0 and presence of anxiety coded as 1 ), and depression with comorbid anxiety (no depression with comorbid anxiety coded as 0 and presence of depression with comorbid anxiety coded as 1 ). The variables with $p<0.1$ were entered into multiple logistic regression models to assess their association with depression, anxiety, and depression with comorbid anxiety. The Hosmer-Lemeshow goodness-of-fit test was referred as the indicator of the goodness-of-fit of the regression models (test finding 
with $p>0.05$ denoted good model fit). $p$-value $<0.05$ were considered statistically significant. All the $p$-values were two-tailed. There were no missing values.

\section{Results}

\section{Characteristics of the study participants}

The demographic characteristics, QoL scores, and psychological complications of the participants are summarized in Table 1. Initially, 376 eligible subjects were invited to participate in this study, but 50 refused to participate, citing various reasons. The final sample size was 326 participants, with a response rate of $86.7 \%$. Most participants fell within the age group of $31-60$ years old ( $n=259,79.4 \%)$, and approximately three-quarters of them were female. Most participants were Malays ( $n=305,93.6 \%)$, and most were married ( $n=283,86.8 \%)$. Most participants had a stable job $(n=261,80.1 \%)$, and more than half of them participated in the study prior to the declaration of COVID-19 as a global pandemic $(n=199,61.0 \%)$. Most participants did not smoke $(n=308,94.5 \%)$, and the mean BMI was 26.87 (SD = 5.52).

The prevalence values of psychological complications were as follows: depression, $23.9 \%(n=78)$; anxiety, $41.7 \%(n=136)$; depression with comorbid anxiety, $19.9 \%(n=65)$; and stress, 31.6\% $(n=103)$. The mean QoL domain scores were as follows: physical health QoL, $69.44($ SD $=$ 12.82); psychological QoL, 71.06 (SD = 12.78); social relationship QoL, 72.40 (SD = 12.82); and environmental QoL, 68.44 (SD = 12.52$)$.

\section{Predictors of depression among the participants}

The association between various demographic characteristics, QoL, and depression among the participants are presented in Table 2. Simple logistic regression analyses indicated that the individual variables significantly associated with depression $(p<0.1)$ included being single, divorced, or widowed (crude OR $=1.87,95 \% \mathrm{Cl}=0.94-3.72, \mathrm{p}=0.074$ ), those who were assessed after COVID-19 was declared as a global pandemic (crude OR $=1.49,95 \% \mathrm{Cl}=1.28-1.86, \mathrm{p}=0.013$ ), those with stress (crude $\mathrm{OR}=17.60,95 \% \mathrm{Cl}=9.36-33.10, \mathrm{p}<0.001$ ), higher physical health QoL score (crude OR $=0.93,95 \% \mathrm{Cl}=0.91-0.96, \mathrm{p}<0.001$ ), higher psychological QoL score (crude OR $=0.93,95 \% \mathrm{Cl}=0.91-$ $0.95, \mathrm{p}<0.001$ ), higher social relationship QoL score (crude OR $=0.95,95 \% \mathrm{Cl}=0.93-0.97, \mathrm{p}<0.001$ ), and higher environmental QoL score (crude OR $=0.94,95 \% \mathrm{Cl}=0.92-0.97, \mathrm{p}<0.001$ ).

Multiple logistic regression analysis revealed that there were only two variables that predicted higher odds of depression, that is, assessment after COVID-19 was declared as a global pandemic (adjusted OR $=2.99,95 \% \mathrm{Cl}=1.41-6.35, \mathrm{p}=0.006$ ) and stress (adjusted OR $=16.00,95 \% \mathrm{Cl}$ $=7.84-32.63, \mathrm{p}<0.001)$. There was only one variable that was protective against depression-that is, higher psychological QoL score (adjusted $\mathrm{OR}=0.83,95 \% \mathrm{Cl}=0.69-0.99, \mathrm{p}=0.032$ ). The Cox and Snell $\mathrm{R}^{2}$ of the multiple logistic regression model was 0.332 ( $\mathrm{p}<0.001$ ), and the Hosmer-Lemeshow goodness-of-fit test $\left(\chi^{2}=12.43, p=0.133\right)$ indicated acceptable fit of the model.

\section{Predictors of anxiety among the participants}

The association between various demographic characteristics, QoL, and anxiety among the participants are illustrated in Table 3. Simple logistic regression analyses demonstrated that those within the age group of $31-60$ years (crude $0 \mathrm{R}=0.48,95 \% \mathrm{Cl}=0.21-1.08, \mathrm{p}=0.075$ ); those who were single, divorced, or widowed (crude $\mathrm{OR}=2.69,95 \% \mathrm{Cl}=1.34-5.23, \mathrm{p}=0.003$ ); those who were experiencing stress (crude OR = 23.81, 95\% Cl = 12.44-45.55, $\mathrm{p}<0.001$ ); higher physical health QoL score (crude OR $=0.79,95 \% \mathrm{Cl}=0.73-0.85, \mathrm{p}<0.001$ ); higher psychological QoL score (crude OR $=0.82,95 \% \mathrm{Cl}=0.75-0.89, \mathrm{p}<0.001$ ); higher social relationship QoL score (crude OR $=0.65,95 \% \mathrm{Cl}=$ $0.56-0.75, \mathrm{p}<0.001$ ); and higher environmental QoL score (crude OR=0.86, $95 \% \mathrm{Cl}=0.80-0.91, \mathrm{p}<0.001$ ) were significantly likely to have anxiety $(p<0.1)$.

The multiple logistic regression analysis illustrated that participants being in stress (adjusted OR $=19.72,95 \% \mathrm{Cl}=9.75-39.89, \mathrm{p}<0.001$ ) represented the only variable that significantly predicted higher odds of anxiety. Higher physical health QoL score (adjusted OR $=0.85,95 \% \mathrm{Cl}=$ 0.75-0.97, $p=0.021$ ) and higher social relationship QoL score (adjusted OR $=0.70,95 \% \mathrm{Cl}=0.55-0.90, p=0.009$ ) were protective against anxiety. The Cox and Snell $R^{2}$ of the multiple logistic regression model was $0.389(p=0.003)$, and the Hosmer-Lemeshow goodness-of-fit test $\left(x^{2}=5.29, p=0.726\right)$ indicated acceptable fit of the model.

\section{Predictors of depression with comorbid anxiety among the participants}

The association between various demographic characteristics, QoL, and depression with comorbid anxiety among the participants are illustrated in Table 4. Simple logistic regression analyses revealed that the variables which were significantly associated with depression with comorbid anxiety $(p<0.1)$ included Malay nationality (crude $\mathrm{OR}=0.37,95 \% \mathrm{Cl}=0.15-0.94, \mathrm{p}=0.089$ ); being single, divorced, or widowed (crude $\mathrm{OR}=2.61,95 \% \mathrm{Cl}=1.36-5.01, \mathrm{p}=0.037$ ); assessment after COVID-19 was declared as a global pandemic (crude OR $=2.06,95 \% \mathrm{Cl}=$ 1.12-3.77, $\mathrm{p}=0.020$ ); being in stress (crude OR = 39.77, 95\% Cl = 17.04-92.81, $\mathrm{p}<0.001$ ); higher physical health QoL score (crude OR = 0.77, 
95\% Cl = 0.70-0.85, $\mathrm{p}<0.001$ ); higher psychological QoL score (crude OR $=0.73,95 \% \mathrm{Cl}=0.65-0.81$, $\mathrm{p}<0.001$ ); higher social relationship QoL score (crude $\mathrm{OR}=0.66,95 \% \mathrm{Cl}=0.57-0.78, \mathrm{p}<0.001$ ); and higher environmental QoL score $(\mathrm{crude} \mathrm{OR}=0.83,95 \% \mathrm{Cl}=0.76-0.89, \mathrm{p}<0.001)$.

The multiple logistic regression analysis pinpointed that there were only two variables that significantly predicted higher odds of depression with comorbid anxiety, which were assessment after COVID-19 was declared as a global pandemic (adjusted OR $=3.19,95 \% \mathrm{Cl}=1.37-7.45, \mathrm{p}=$ 0.005 ) and being in stress (adjusted $\mathrm{OR}=40.44,95 \% \mathrm{Cl}=15.90-102.87, \mathrm{p}<0.001$ ). The only variable that was protective against depression with comorbid anxiety among the participants was a higher psychological QoL score (adjusted $\mathrm{OR}=0.82,95 \% \mathrm{Cl}=0.68-0.98, \mathrm{p}=0.041$ ). The Cox and Snell $\mathrm{R}^{2}$ of the multiple logistic regression model was $0.366(p<0.001)$, and the Hosmer-Lemeshow goodness-of-fit test $\left(\chi^{2}=9.37, p=\right.$ 0.312) indicated acceptable fit of the model.

\section{Discussion}

This study determined the prevalence of depression, anxiety, depression with comorbid anxiety, and the association between various demographic factors, QoL, and the mentioned psychological complications among participants from urban communities. We found that $23.9 \%$ of the participants had depression, $41.7 \%$ had anxiety, and $19.9 \%$ had depression with comorbid anxiety. Our findings showed a relatively high prevalence of depression as compared with the results of a few studies on the Malaysian urban population, which reported the prevalence of depression in the range of 10.30\%-13.98\% (Tan dan Yadav, 2012; Kader Maideen et al., 2014; Cheah et al., 2020). Nevertheless, our study revealed a lower prevalence of depression compared with the prevalence reported in other Asian countries, such as India and China, where the range was reported as 33\%-35\% (Firdaus and Ahmad, 2014; Li et al., 2019). Again, the prevalence of anxiety reported in our study was much higher than that reported in another study on the prevalence of anxiety in Malaysian communities (in which it was $8.2 \%$; Kader Maideen et al., 2015). In comparison with other Asian countries, the prevalence of anxiety found in our study was comparable to that reported in the Chinese community (reported as 41.12\%; Guo et al., 2016). In contrast, the prevalence of depression with comorbid anxiety found in our study was relatively lower than that of another study of comorbidity of depression and anxiety in the Malaysian community (reported as $67.2 \%$; Kader Maideen et al., 2014). The discrepancy in the prevalence of anxiety, depression, and comorbid depression and anxiety between our study and other studies in the Malaysian community may be attributed to the different screening tools used. In addition, the emergence of the COVID-19 pandemic may also elevate the prevalence of depression, anxiety, and depression with comorbid anxiety in our study. When we compared the prevalence of depression and anxiety in our study to that of a study of depression and anxiety in 576 Malaysian urban dwellers who attended primary healthcare clinics, which also used the DASS-21 as a screening instrument (anxiety: 44.5\%; depression: 20.5\%; Abd Rahman et al., 2020), similar prevalence values were noted.

There were only two factors which registered significant association with higher odds of depression, which were as follows: comorbid stress, which increased the odds of acquiring depression by more than 17-fold compared with an absence of comorbid stress; and undergoing assessment after the declaration of COVID-19 as a global pandemic, which increased the odds of depression by almost threefold compared with undergoing assessment before declaration of COVID-19 as a global pandemic. In contrast, a higher level of perceived psychological QoL was protective against depression by reducing the odds of depression by 1.25 -fold, as indicated by our findings. The relationship of chronic stress as a risk factor for developing depression can be understood by referring to the hypothalamic-pituitary-adrenal axis (HPA axis) hyperactivation resulting from exposure to chronic stress. Elevated corticotropin-releasing hormone (CRH) has been shown to induce depressive symptoms, such as insomnia, altered locomotor activity, low appetite, and reduced libido. In addition, excessive cortisol levels in response to chronic stress may also damage the hippocampus in the brain and prevent neurogenesis in the hippocampus. Finally, prolonged stress may increase brain degeneration and reduce the functioning of the hippocampus and prefrontal cortex, leading to an elevated risk of depression (Tafet and Nemeroff, 2016). The association of COVID-19 with the development of depression in our study is consistent with the findings of several studies of the effect of COVID-19 on the general populations in China, Italy, and Turkey, indicating that the odds of depression increased after the occurrence of the COVID-19 pandemic (Ahmed et al., 2020; Gao et al., 2020; Mazza et al., 2020; Ozdin and Ozdin, 2020; Wang et al., 2020a; Wang et al., 2020b). Interestingly, the participants who enrolled in our study after the declaration of COVID-19 as a global pandemic underwent assessment after the movement control order was lifted for 3 weeks (after the study recommenced from July 2020 to August 2020). Hence, our study pinpointed that the increased odds of depression may persist even after the movement lockdown imposed by the government had been lifted, indicating that the stress and fear of contracting the COVID-19 infection and the negative consequences that followed may predispose individuals to depression, independent of the effect of the movement lockdown on mental health. The inverse relationship between psychological QoL and depression is well documented; lower psychological QoL was reported in depressive patients, while improvement of psychological QoL occurred in treated major affective disorder patients who had just been discharged from inpatient wards (Olusina and Ohaeri, 2003; Shumye et al., 2019). Hence, it is not surprising that higher perceived psychological QoL reduced the odds of depression, as reported by this study.

Our study reported that the presence of comorbid stress was the only factor significantly associated with increased odds of anxiety, while social relationship QoL and physical health QoL reduced the odds of anxiety among the participants. Chronic stress is a sustained threat, 
whether it is a potential or actual threat that leads to an aversive emotional state. Chronic stress induces deleterious effects on the homeostasis of the biological system, particularly resulting in HPA axis dysregulation, which leads to increased allostatic load and subsequently increases the risk of anxiety disorders (Patriquin and Mathew, 2017). This may explain the association between the presence of comorbid stress and higher odds of anxiety in our study. The protective effect of higher physical QoL against the occurrence of anxiety can be explained by the inverse relationship between physical health and anxiety. Poor and moderate self-rated health is predictive of higher odds of acquiring anxiety by 4-fold and 1.7-fold, respectively (Hossain et al., 2020). Conversely, a meta-analysis of 14 cohorts of 13 prospective studies reported that high self-reported physical activity reduced the odds of developing anxiety by 1.35-fold and high self-reported physical activity was also protective against development of agoraphobia and posttraumatic stress disorder; these results were evident in Asian and European populations, as well as across different age groups, from children/adolescents to adults (Schuch et al., 2019). As with the association between social relationships and anxiety, cross-sectional data from the assessment of spouse or partner relationships of 4,988 Irish adults identified that positive partner interaction was significantly associated with reduced likelihood of anxiety (Santini et al., 2015). Nevertheless, social disconnectedness predicted a higher occurrence of anxiety symptoms (Santini et al., 2020). These findings support the association between high social relationship QoL and lower odds of anxiety found in this study.

The associated factors of depression with comorbid anxiety were found to be similar to those of depression, in which participants with comorbid stress and those who underwent assessment after the declaration of COVID-19 were found to have higher odds of depression with comorbid anxiety, while higher psychological QoL was associated with lower odds of depression and comorbid anxiety. Comorbid stress association with increase odds of depression with comorbid anxiety, may be due to the effect of chronic stress on the HPA axis: Inducing CRH and cortisol dysregulation, as well as disruption of the normal functioning of the hippocampus and prefrontal cortex, increased the risk of developing depression with comorbid anxiety among the participants (Tafet and Nemeroff, 2016; Patriquin and Mathew, 2017). Our finding of higher odds of depression with comorbid anxiety is in line with the finding reported by a study of the psychological effect of COVID-19 in 4,872 Chinese adults, which indicated that the prevalence of depression with comorbid anxiety was 19.4\% (Gao et al., 2020). The association between higher psychological QoL and lower odds of depression with comorbid anxiety was also well supported by similar findings reported by other studies of the relationship between psychological QoL and depression and anxiety (Olusina and Ohaeri, 2003; Shumye et al., 2019; Woon et al., 2020).

Our study highlights a few public health implications. First, since comorbid stress and fear of being infected with COVID-19 elevate the odds of acquiring depression and depression with comorbid anxiety, while better psychological QoL is protective against depression and depression with comorbid anxiety in the urban population, at the time when COVID-19 is still prevalent globally, there is a need for public health authorities and mental health providers to provide online psychotherapy to alleviate chronic stress and improve psychological QoL among urban dwellers. This will require the mobilization and preparation of counselors, psychologists, and psychiatrists to offer this new norm of mental health service to the public. Second, as higher social relationship QoL is protective against anxiety, public health authorities and government agencies should intensively promote the use of online social platforms, such as videoconferencing and web-conferencing applications, to sustain social communication and social relationships among the people in urban communities when COVID-19 infection is still prevalent and social distancing has become the current norm in daily living. This measure may be valuable to curb the increasing likelihood of anxiety in urban communities. Finally, since better physical health QoL is protective against anxiety, considering the current situation where social distancing is the new norm in our daily living and to avoid the disruption of continuous follow-up of patients with pre-existing medical illnesses in the urban communities, telemedicine-which involves treating doctors' online consultation with those who have pre-existing medical illnesses-may be an alternative to address the increasing prevalence of anxiety in urban communities.

Our study has some limitations. First, the causal relationship between various factors and the occurrence of anxiety, depression, and depression with comorbid anxiety could not be evaluated due to the cross-sectional design of this study. Second, the demographic distributions of the participants in this study did not reflect the demographic distributions of the Malaysian urban population. Hence, our study findings may not be generalized to the entire urban population of the country. Third, this study utilized the DASS-21 to assess the prevalence of anxiety, depression, and stress in the participants. Although the cut-off score for depression, anxiety, and stress was evaluated for caseness in DASS21 , it is a self-reported symptom screening instrument, and it is not intended to be used as a diagnostic tool. Hence, future studies using diagnostic tools, such as the Structural and Clinical Interview for DSM or Mini International Neuropsychiatric Interview are recommended to confirm our findings. Finally, we did not record the respondents' education level and monthly income, which could be confounding factors that could have influenced our findings. Notwithstanding the above limitations, this study provided valuable data to fill the gap in the literature on the prevalence of psychological complications and their associated factors in urban communities. This study also added valuable information on the psychological effect of COVID-19 on the urban population, independent of the effect of the movement lockdown.

\section{Conclusion}

This study investigated the prevalence of anxiety, depression, and depression with comorbid anxiety among Malaysian urban dwellers and recorded a relatively high prevalence of these psychological complications compared with other Malaysian studies. We found that comorbid

Page 6/12 
stress, the COVID-19 pandemic, physical health, psychological QoL, and social relationship QoL were significantly associated with depression, anxiety, and depression with comorbid anxiety. Our study findings led us to recommend the following measures: (1) use of online psychotherapy, (2) promotion of online social platforms to sustain social communications and social relationships, and (3) the use of telemedicine to curb the increasing trend of depression and anxiety among the urban population as the COVID-19 pandemic is still widespread and the war against this infection pandemic is ongoing.

\section{Declarations}

\section{Conflict of Interest}

All the authors declare that they have no competing interests.

\section{References}

Abd Rahman,I R., Idris, I. B., \& Ibrahim, H. (2020). Risk factors of depression, anxiety and stress among adults attending primary health clinics in an urban area in Klang Valley, Malaysia. Malaysian Journal of Medicine and Health Sciences, 16(1), 240-246.

Ahmed, M. Z., Oli, A., Zhou, A. B., Sang, H. B., Liu, S. Y., Akbaruddin, A. (2020). Epidemic of COVID-19 in China and associated psychological problems. Asian Journal of Psychiatry, 51, 10209.

Cheah, Y. K., Azahadi, M., Phang, S. N., \& Abd Manaf, N. H. (2014). Sociodemographic, lifestyle, and health factors associated with depression and generalized anxiety disorder among Malaysian adults. Journal of Primary Care \& Community Health, 11, 1-8.

de Vries, E., Rincon, C. J., Martínez, N. T., Rodriguez, N., Tiemeier, H., Mackenbach, J. P., et al (2018). Housing index, urbanisation level and lifetime prevalence of depressive and anxiety disorders: a cross-sectional analysis of the Colombian national mental health survey. BMJ Open, 8, e019065.

Firdaus, G., \& Ahmad, A. (2014). Temporal variation in risk factors and prevalence rate of depression in urban population: does the urban environment play a significant role? International Journal of Mental Health Promotion, 16(5), 279-288.

Gao, J. L., Zheng, P. P., Jia, Y. N., Chen, H., Mao, Y. M., Chen, S. H., et al. (2020). Mental health problems and social media exposure during COVID-19 outbreak. PLoS One, 15(4), e0231924.

Gruebner, O., Rapp, M. A., Adli, M., Kluge, U., Galea, S., \& Heinz, A. (2017). Cities and mental health. Deutsches Ärzteblatt International, $114,121-$ 127.

Guo, X., Meng, Z., Huang, G., Fan, J., Zhou, W., Ling, W., et al. (2016). Meta-analysis of the prevalence of anxiety disorders in mainland China from 2000 to 2015. Scientific Reports, 6, 28033.

Hasanah, C. I., Naing, L., \& Rahman, A. R. A. (2003). World Health Organization Quality of Life Assessment: Brief Version in Bahasa Malaysia. Medical Journal of Malaysia, 58(1), 79-88.

Hossain, S., Anjum, A., Hasan, M. T., Uddin, M. E., Hossain, M. S., \& Sikder, M. T. (2020). Self-perception of physical health conditions and its association with depression and anxiety among Bangladeshi university students. Journal of Affective Disorders, 263, 282-288.

Kader Maideen, S. F., Mohd. Sidik, S., Rampal, L., \& Mukhtar, F. (2014). Prevalence, associated factors and predictors of depression among adults in the community of Selangor, Malaysia. PLOS ONE, 9(4), e95395.

Kader Maideen, S. F., Mohd Sidik, S., Rampal, L., \& Mukhtar, F. (2015). Prevalence, associated factors and predictors of anxiety: a community survey in Selangor, Malaysia. BMC Psychiatry, 15, 262.

Li, G., Mei, J., You, J., Miao, J., Song, X., Sun, W., et al. (2019). Sociodemographic characteristics associated with adolescent depression in urban and rural areas of Hubei province: a cross-sectional analysis. BMC Psychiatry, 19, 386.

Lovibond, S. H., \& Lovibond, P. F. (1995). Manual for the Depression Anxiety Stress Scales. Sydney: Psychology Foundation of Australia.

Mazza, C., Ricci, E., Biondi, S., Colasanti, M., Ferracuti, S., Napoli, C., et al. (2020). A nationwide survey of psychological distress among Italian people during the COVID-19 pandemic: immediate psychological responses and associated factors. International Journal of Environmental Research and Public Health, 17, 3165. 
Musa, R., Fadzil, M. A., \& Zain, A. (2007). Translation, validation and psychometric properties of Bahasa Malaysia version of the Depression Anxiety and Stress Scales (DASS). ASEAN Journal of Psychiatry, 8(2), 82-89.

Olusina, A. K., \& Ohaeri, J. U. (2003). Subjective quality of life of recently discharged Nigerian psychiatric patients. Social Psychiatry and Psychiatric Epidemiology, 38(12), 707-714.

Özdin, S., \& Özdin, S. B. (2020). Levels and predictors of anxiety, depression and health anxiety during COVID-19 pandemic in Turkish society: The importance of gender. International Journal of Social Psychiatry, 66(5), 504-511.

Patriquin, M. A., \& Mathew, S. J. (2017). The neurobiological mechanisms of generalized anxiety disorder and chronic stress. Chronic Stress, 1, $1-10$.

Schuch, F. B., Stubbs, B., Meyer, J., Heissel, A., Zech, P., Vancampfort, D., et al. (2019). Physical activity protects from incident anxiety: A metaanalysis of prospective cohort studies. Depression and Anxiety, 36(9), 846-858.

Shumye, S., Belayneh, Z. \& Mengistu, N. (2019). Health related quality of life and its correlates among people with depression attending outpatient department in Ethiopia: a cross sectional study. Health and Quality of Life Outcomes, 17, 169.

Tafet, G. E., Nemeroff, C. B. (2016). The links between stress and depression: psychoneuroendocrinological, genetic, and environmental interactions. Journal of Neuropsychiatry and Clinical Neuroscience, 28, 77-88.

Tan, K. L., \& Yadav, H. (2012). Depression among the urban poor in Peninsular Malaysia: A community based cross-sectional study. Journal of Health Psychology, 18(1), 121-127.

The WHOQOL Group. (1998). Development of the World Health Organization WHOQOL-BREF Quality of Life assessment. Psychological Medicine, 28(3), 551-558.

United Nation Department of Economic and Social Affairs (2018). World urbanization prospects. The 2018 revision. https://www.un.org/development/desa/pd/sites/www.un.org.development.desa.pd/files/files/documents/2020/Jan/un_2018_wup_report.pdf. Accessed 8 October 2020.

Wang, C. Y., Pan, R. Y., Wan, X. Y., Tan, Y. L., Xu, L. K., Ho, C. S., et al. (2020). Immediate psychological responses and associated factors during the Initial Stage of the 2019 Coronavirus Disease (COVID-19) epidemic among the general population in China. International Journal of Environmental Research and Public Health, 17, 1729.

Wang, C.Y., Pan, R. Y., Wan, X. Y., Tan, Y. L., Xu, L. K., Mclntyre, R. S., et al. (2020b). A longitudinal study on the mental health of general population during the COVID-19 epidemic in China. Brain Behavior and Immunity, 87, 40-48.

Woon, L. S-C., Sidi, H., Ravindran, A., Gosse, P. J., Mainland, R. L., Kaunismaa, E. S., et al. (2020). Depression, anxiety, and associated factors in patients with diabetes: evidence from the anxiety, depression, and personality traits in diabetes mellitus (ADAPT-DM) study. BMC Psychiatry, 20, 227.

Xiong, J., Lipsitz, O., Nasri, F., Lui, L. M. W., Gill, H., Phan, L., et al. (2020). Impact of COVID-19 pandemic on mental health in the general population: A systematic review. Journal of Affective Disorder, 277, 55-64.

\section{Tables}

Table 1. Sociodemographic characteristics, the quality of life scores, and prevalence of depression, anxiety, and depression with comorbid anxiety among the participants 


\begin{tabular}{|c|c|c|}
\hline Variables & $n$ & $\%$ \\
\hline \multicolumn{3}{|l|}{ Age: } \\
\hline 18-30 years old & 26 & 8.0 \\
\hline $31-60$ years old & 259 & 79.4 \\
\hline$>60$ years old & 41 & 12.6 \\
\hline \multicolumn{3}{|l|}{ Gender: } \\
\hline Male & 88 & 27.0 \\
\hline Female & 238 & 73.0 \\
\hline \multicolumn{3}{|l|}{ Ethnicity: } \\
\hline Malay & 305 & 93.6 \\
\hline Chinese & 8 & 2.5 \\
\hline Indian & 13 & 4.0 \\
\hline \multicolumn{3}{|l|}{ Employment status: } \\
\hline Employed & 261 & 80.1 \\
\hline Unemployed/students & 65 & 19.9 \\
\hline \multicolumn{3}{|l|}{ Marital status: } \\
\hline Married & 283 & 86.8 \\
\hline Single & 32 & 9.8 \\
\hline Divorced/widowed & 11 & 3.4 \\
\hline \multicolumn{3}{|l|}{ Participation time: } \\
\hline Before declaration of COVID-19 pandemic & 199 & 61.0 \\
\hline After declaration of COVID-19 pandemic & 127 & 39.0 \\
\hline \multicolumn{3}{|l|}{ Cigarette smoking: } \\
\hline Smokers & 18 & 5.5 \\
\hline Non-smokers & 308 & 94.5 \\
\hline BMI & $26.87^{\mathrm{a}}$ & $5.52^{\mathrm{b}}$ \\
\hline \multicolumn{3}{|l|}{ Depression: } \\
\hline No & 248 & 76.1 \\
\hline Yes & 78 & 23.9 \\
\hline \multicolumn{3}{|l|}{ Anxiety: } \\
\hline No & 190 & 58.3 \\
\hline Yes & 136 & 41.7 \\
\hline \multicolumn{3}{|l|}{ Stress: } \\
\hline No & 223 & 68.4 \\
\hline Yes & 103 & 31.6 \\
\hline \multicolumn{3}{|l|}{ Depression with comorbid anxiety: } \\
\hline No & 261 & 80.1 \\
\hline Yes & 65 & 19.9 \\
\hline \multicolumn{3}{|l|}{ WHOQoL-BREF scores: } \\
\hline Physical health QoL subscale mean score & $69.44^{\mathrm{a}}$ & $12.82^{\mathrm{b}}$ \\
\hline Psychological QoL subscale mean score & $71.06^{\mathrm{a}}$ & $12.78^{\mathrm{b}}$ \\
\hline Social QoL subscale mean score & $72.40^{\mathrm{a}}$ & $12.82^{\mathrm{b}}$ \\
\hline Environment QoL subscale mean score & $68.44^{\mathrm{a}}$ & $\begin{array}{l}12.82^{\circ} \\
12.52^{b}\end{array}$ \\
\hline
\end{tabular}

a mean, ${ }^{b}$ standard deviation

Table 2. Association between sociodemographic characteristics, quality of life, and depression among the participants 


\begin{tabular}{|c|c|c|}
\hline Variables & $\begin{array}{l}\text { Crude OR } \\
(95 \% \mathrm{CI})\end{array}$ & $\begin{array}{l}\text { Adjusted OR } \\
\quad(95 \% \mathrm{CI})\end{array}$ \\
\hline \multicolumn{3}{|l|}{ Age: } \\
\hline $18-30$ years & 1 & - \\
\hline $31-60$ years & $0.75(0.30-1.87)$ & \\
\hline$>60$ years old & $1.57(0.54-4.57)$ & \\
\hline \multicolumn{3}{|l|}{ Gender: } \\
\hline Male & 1 & - \\
\hline Female & $1.31(0.72-2.38)$ & \\
\hline \multicolumn{3}{|l|}{ Ethnicity: } \\
\hline Non-Malay & 1 & - \\
\hline Malay & $0.48(0.19-1.22)$ & \\
\hline \multicolumn{3}{|l|}{ Employment status: } \\
\hline Employed & 1 & - \\
\hline Unemployed/students & $1.05(0.56-1.97)$ & \\
\hline \multicolumn{3}{|l|}{ Marital status: } \\
\hline Married & 1 & 1 \\
\hline Single/divorcee/widow/widower & $1.87(0.94-3.72) *$ & $1.00(0.39-2.60)$ \\
\hline \multicolumn{3}{|l|}{ Participation time: } \\
\hline Before declaration of COVID-19 pandemic & 1 & 1 \\
\hline $\begin{array}{l}\text { After declaration of COVID-19 pandemic } \\
\text { Cigarette smoking: }\end{array}$ & Cigarette smoking: & $2.99(1.41-6.35)^{* *}$ \\
\hline Smokers & 1 & - \\
\hline Non-smokers & $1.61(0.45-5.71)$ & \\
\hline BMI & $0.99(0.95-1.04)$ & \\
\hline \multicolumn{3}{|l|}{ Stress: } \\
\hline No & 1 & 1 \\
\hline Yes & $17.60(9.36-33.10) *$ & $16.00(7.84-32.63) * *$ \\
\hline \multicolumn{3}{|l|}{ WHOQoL-BREF scores: } \\
\hline Physical health QoL subscale mean score & $0.93(0.91-0.96) *$ & $0.92(0.80-1.06)$ \\
\hline Psychological QoL subscale mean score & $0.93(0.91-0.95) *$ & $0.83(0.69-0.99) * *$ \\
\hline Social QoL subscale mean score & $0.95(0.93-0.97) *$ & $0.83(0.65-1.05)$ \\
\hline Environment QoL subscale mean score & $0.94(0.92-0.97) *$ & $1.12(0.96-1.29)$ \\
\hline
\end{tabular}

* statistical significance at $p<0.1$; ** statistical significance at $\mathrm{p}<0.05$; ${ }^{\mathrm{a}}=$ absence of depression coded 0 (reference), presence of depression coded $1 ;{ }^{\mathrm{b}}=$ absence of depression coded 0 (reference), presence of depression coded 1 , multiple logistic regression model reported Cox and Snell $R^{2}=0.332$, $p<0.001$, Hosmer-Lemeshow goodness-of-fit test $\left(\chi^{2}=12.43, p=0.133\right)$

Table 3. Association between sociodemographic characteristics, quality of life, and anxiety among the participants 


\begin{tabular}{|c|c|c|}
\hline Variables & $\begin{array}{l}\text { Crude OR }^{\mathrm{a}} \\
(95 \% \mathrm{CI})\end{array}$ & $\begin{array}{l}\text { Adjusted OR }{ }^{\mathrm{b}} \\
(95 \% \mathrm{CI})\end{array}$ \\
\hline \multicolumn{3}{|l|}{ Age: } \\
\hline 18-30 years & 1 & 1 \\
\hline $31-60$ years & $0.48(0.21-1.08)^{*}$ & $0.38(0.12-1.28)$ \\
\hline$>60$ years old & $0.63(0.24-1.71)$ & $0.45(0.11-1.85)$ \\
\hline \multicolumn{3}{|l|}{ Gender: } \\
\hline Male & 1 & - \\
\hline Female & $1.27(0.77-2.10)$ & \\
\hline \multicolumn{3}{|l|}{ Ethnicity: } \\
\hline Non-Malay & 1 & - \\
\hline Malay & $0.51(0.21-1.26)$ & \\
\hline \multicolumn{3}{|l|}{ Employment status: } \\
\hline Employed & 1 & - \\
\hline Unemployed/students & $0.78(0.45-1.36)$ & \\
\hline \multicolumn{3}{|l|}{ Marital status: } \\
\hline Married & 1 & 1 \\
\hline Single/divorcee/widow/widower & $2.69(1.34-5.23) *$ & $1.27(0.49-3.32)$ \\
\hline \multicolumn{3}{|l|}{ Participation time: } \\
\hline Before declaration of COVID-19 pandemic & 1 & - \\
\hline After declaration of COVID-19 pandemic & $0.81(0.51-1.27)$ & \\
\hline \multicolumn{3}{|l|}{ Cigarette smoking: } \\
\hline Smokers & 1 & - \\
\hline Non-smokers & $1.92(0.67-5.53)$ & \\
\hline BMI & $1.00(0.97-1.05)$ & \\
\hline \multicolumn{3}{|l|}{ Stress: } \\
\hline No & 1 & 1 \\
\hline Yes & $23.81(12.44-45.55)^{*}$ & $19.72(9.75-39.89)^{* *}$ \\
\hline \multicolumn{3}{|l|}{ WHOQoL-BREF scores: } \\
\hline Physical health QoL subscale mean score & $0.79(0.73-0.85) *$ & $0.85(0.75-0.97) * *$ \\
\hline Psychological QoL subscale mean score & $0.82(0.75-0.89) *$ & $1.13(0.95-1.35)$ \\
\hline Social QoL subscale mean score & $0.65(0.56-0.75) *$ & $0.70(0.55-0.90) * *$ \\
\hline Environment QoL subscale mean score & $0.86(0.80-0.91) *$ & $1.02(0.89-1.16)$ \\
\hline
\end{tabular}

* statistical significance at $\mathrm{p}<0.1 ;{ }^{* \star}$ statistical significance at $\mathrm{p}<0.05 ;{ }^{\mathrm{a}}=$ absence of anxiety coded 0 (reference), presence of anxiety coded 1 ; ${ }^{\mathrm{b}}=$ absence of anxiety coded 0 (reference), presence of anxiety coded 1, multiple logistic regression model reported Cox and Snell $R^{2}=0.389, p=0.003$, Hosmer-Lemeshow goodness-of-fit test $\left(\chi^{2}=5.29, p=0.726\right)$

Table 4. Association between socio-demographic characteristics, quality of life, and depression with comorbid anxiety among the participants 


\begin{tabular}{|c|c|c|}
\hline Variables & $\begin{array}{l}\text { Crude OR }^{a} \\
(95 \% \mathrm{CI})\end{array}$ & $\begin{array}{l}\text { Adjusted OR }{ }^{\mathrm{b}} \\
(95 \% \mathrm{CI})\end{array}$ \\
\hline \multicolumn{3}{|l|}{ Age: } \\
\hline 18-30 years old & 1 & - \\
\hline 31-60 years old & $0.74(0.28-1.94)$ & \\
\hline$>60$ years old & $1.38(0.44-4.29)$ & \\
\hline \multicolumn{3}{|l|}{ Gender: } \\
\hline Male & 1 & - \\
\hline Female & $1.29(0.68-2.45)$ & \\
\hline \multicolumn{3}{|l|}{ Ethnicity: } \\
\hline Non-Malay & 1 & 1 \\
\hline Malay & $0.37(0.15-0.94)^{*}$ & $0.67(0.15-2.95)$ \\
\hline \multicolumn{3}{|l|}{ Employment status: } \\
\hline Employed & 1 & - \\
\hline Unemployed/students & $0.72(0.39-1.33)$ & \\
\hline \multicolumn{3}{|l|}{ Marital status: } \\
\hline Married & 1 & 1 \\
\hline Single/divorcee/widow/widower & $2.61(1.36-5.01)^{*}$ & $0.59(0.20-1.71)$ \\
\hline \multicolumn{3}{|l|}{ Participation time: } \\
\hline Before declaration of COVID-19 pandemic & 1 & 1 \\
\hline After declaration of COVID-19 pandemic & $2.06(1.12-3.77)^{*}$ & $3.19(1.37-7.45) * *$ \\
\hline Cigarette smoking: & & - \\
\hline Smokers & 1 & \\
\hline Non-smokers & $2.06(0.46-9.18)$ & - \\
\hline BMI & $0.99(0.94-1.04)$ & \\
\hline \multicolumn{3}{|l|}{ Stress: } \\
\hline No & 1 & 1 \\
\hline Yes & $39.77(17.04-92.81)^{*}$ & $40.44(15.90-102.87)^{* *}$ \\
\hline \multicolumn{3}{|l|}{ WHOQoL-BREF scores: } \\
\hline Physical health QoL subscale mean score & $0.77(0.70-0.85)^{*}$ & $0.93(0.79-1.10)$ \\
\hline Psychological QoL subscale mean score & $0.73(0.65-0.81)^{*}$ & $0.82(0.68-0.98) * *$ \\
\hline Social QoL subscale mean score & $0.66(0.57-0.78) *$ & $0.89(0.69-1.16)$ \\
\hline Environment QoL subscale mean score & $0.83(0.76-0.89)^{*}$ & $1.07(0.91-1.26)$ \\
\hline
\end{tabular}

* statistical significance at $p<0.1$; ${ }^{\star \star}$ statistical significance at $p<0.05$; ${ }^{a}=$ absence of depression with comorbid anxiety coded 0 (reference), presence of depression with comorbid anxiety coded $1 ;{ }^{b}=$ absence of depression with comorbid anxiety coded 0 (reference), presence of depression with comorbid anxiety coded 1, multiple logistic regression model reported Cox and Snell $R^{2}=0.366, p<0.001$, Hosmer-Lemeshow goodness-of-fit test $\left(\chi^{2}=9.37, p=0.312\right)$ 